Revue

Revue de l'histoire des religions

de Ihistoire des religions

Genève, refuge et migrations ( $\mathrm{XVI} \mathrm{e}^{\mathrm{e}} \mathrm{XVII}{ }^{\mathrm{e}}$ siècles)

\title{
Sabine Frommel et Laurent Lecomte (dir.), La place
} du chour

Paris, Picard et Rome, Campisano, 2012

Alain Rauwel

\section{(2) OpenEdition}

Journals

Édition électronique

URL : http://journals.openedition.org/rhr/8356

DOI : 10.4000/rhr.8356

ISSN : 2105-2573

Éditeur

Armand Colin

Édition imprimée

Date de publication : 1 mars 2015

Pagination : 91-93

ISBN : 9782200929657

ISSN : 0035-1423

Référence électronique

Alain Rauwel, «Sabine Frommel et Laurent Lecomte (dir.), La place du chœur », Revue de l'histoire des religions [En ligne], 1 | 2015, mis en ligne le, consulté le 22 septembre 2020. URL : http://

journals.openedition.org/rhr/8356; DOI : https://doi.org/10.4000/rhr.8356

Ce document a été généré automatiquement le 22 septembre 2020.

Tous droits réservés 


\section{Sabine FROMMEL et Laurent LECOMTE (dir.), La place du chœur}

Paris, Picard et Rome, Campisano, 2012

Alain Rauwel

\section{RÉFÉRENCE}

Sabine Frommel et Laurent Lecomte (dir.), La place du chœur, Paris, Picard et Rome, Campisano, 2012, 300 p., 27 cm, 65 €, ISBN 978-2-7084-0928-6.

1 L'abondant colloque tenu à l'Institut National d'Histoire de l'Art en 2007 s'inscrit dans une tradition bien française d'archéologie fonctionnelle des lieux de culte, en opposition à une pratique monographique et formaliste de la description architecturale indifférente aux usages des espaces considérés. Le pari des organisateurs aura été d'élargir les perspectives au-delà des études paléochrétiennes et médiévales, terrain d'élaboration et d'élection de la méthode, en consacrant la grande majorité des communications au deuxième millénaire. De ce point de vue, la division de l'ouvrage pourra sembler étrange : une première partie veut conduire « des origines à la réforme grégorienne ", mais accorde une grande place à l'âge d'or du gothique! Nul ne songe à nier l'importance du moment grégorien pour toute la Chrétienté médiévale; pour autant, la chronologie semble ici violentée. La deuxième partie est entièrement consacrée à «la Renaissance», dont on peut se demander si elle fournit en tant que telle un cadre bien pertinent pour une interrogation sur les rapports entre culte et architecture. Le troisième ensemble, plus cohérent, porte sur «le concile de Trente et ses conséquences ", jusqu'à la fin de l'Ancien Régime.

2 Il est inévitable que les études rassemblées dans un tel recueil soient de valeur très inégale. Les périodes hautes sont parmi les mieux traitées, confiées qu'elles sont à des maîtres indiscutés. Sible de Blaauw, à qui l'archéologie chrétienne doit tant, pose d'emblée la question cruciale du vocabulaire : le chorus dans l'Antiquité n'est pas un lieu mais un groupe, celui des chantres. Le problème est donc aussi social que spatial : qui, 
dans l'église, a droit à la zone privilégiée voisine de l'autel, et à quel titre ? C'est encore plus nettement le cas aux temps carolingiens, comme l'établit fermement Christian Sapin : même si la dimension dévotionnelle est à prendre en compte, la multiplication des clôtures de chœur, les phénomènes de surélévation (difficilement repérables en archéologie, où les traces des emmarchements sont ténues et rarement relevées) accompagnent exactement les nombreuses interdictions adressées aux laïcs de pénétrer dans l'espace des clercs. Un document très connu comme le plan de Saint-Gall garde ici toute son importance, montrant dans leur intégralité idéale des systèmes que l'on ne trouve plus ailleurs que par bribes.

3 La fin du Moyen Âge fait l'objet d'appréciations plus erratiques. Tandis que Christian Freygang livre une belle analyse du chœur de Cologne, Alain Erlande-Brandenburg propose quelques considérations sur un échantillon de cathédrales gothiques. Ses formules laissent parfois perplexe : en quoi le fait que l'évêque de Senlis commence sa cathédrale par la façade peut-il bien traduire un «choix démocratique »? Panayota Volti, elle, s'attaque à un sujet de la plus haute importance, les chœurs de moniales (ici à partir du cas mendiant). Ces structures sont mal connues, extrêmement variables dans le temps et dans l'espace, et il serait grand temps de leur consacrer une synthèse. On ne la trouvera pas dans l'esquisse proposée, plus assertive que démonstrative, et affaiblie par une permanente incertitude du vocabulaire. Fort heureusement, pour les $\mathrm{XVII}^{\mathrm{e}}$ et XVIII ${ }^{\mathrm{e}}$ siècles, le même problème est magistralement étudié par Laurent Lecomte qui, malgré la disparition de la plupart des témoins, fait le meilleur usage des textes réglementaires et de plans somme toute fort nombreux pour décrire ce que l'on appelle désormais « l'église intérieure ", en une formule à double sens qui peut aussi évoquer la contemplation à laquelle doivent vaquer les sœurs, au plus loin des regards. Même en ces temps d'uniformisation liturgique, les diversités régionales restent fortes : ainsi du chœur axial de retro à la romaine, très peu utilisé en France où s'impose le modèle à angle droit, sauf en des cas singuliers comme celui de Port-Royal.

4 Les Quattro et Cinquecento, temps de "grande " architecture, bénéficient d'une approche plus conforme aux canons traditionnels de l'histoire de l'art universitaire, comme le manifeste l'article de Sabine Frommel, qui interroge du point de vue des formes liturgiques le Quinto libro d'architettura de Serlio. L'Italie semble d'ailleurs, pour les directeurs du volume, le seul pays européen qui vaille d'être examiné à cette période : ses métropoles seules sont étudiées, à commencer bien sûr par Rome, théâtre du gigantesque chantier de Saint-Pierre, évoqué en connaisseur par Christoph Luitpold Frommel, en passant par Venise, Florence et Palerme. La fringale comparatrice du lecteur, du coup, n'est qu'en partie apaisée, d'autant que les clichés n'ont pas toujours la qualité que l'on serait en droit d'attendre en pareille publication.

On n'est pas surpris de constater que les contributions les plus neuves (parmi lesquelles il faut compter celle de Laurent Lecomte) portent sur la Chrétienté tridentine. La vie rituelle des Temps modernes, longtemps victime des oukases de Dom Guéranger, fait aujourd'hui retour au premier plan des études liturgiques. Judicieusement, l'itinéraire commence ici avec Borromée lui-même, véritablement obsédé par la sanctuarisation cléricale de l'espace cultuel, dans un contexte polémique (Hospinianus, De templis) où les références historiques sont abondamment mobilisées, et trouvent une application immédiate dans les travaux de réaménagement du Duomo de Milan. Les innombrables querelles de préséance suscitées par la réforme nous ramènent avec insistance à la dimension sociale de l'architecture sacrée. D'autres analyses le prouvent, à Bologne, en 
Piémont ou aux Pays-Bas. De ce côté des monts, Mathieu Lours, dans la suite de sa grande thèse, examine « Le chœur en bataille : débats et polémiques sur les chœurs à la romaine dans les cathédrales françaises $d u$ XVIII ${ }^{e}$ siècle ». Les cas particulièrement évocateurs de Metz, de Noyon et de Verdun montrent comment l'enjeu gallican vient pimenter les débats autour des rénovations intérieures. À Verdun, les projets du chanoine de Plaine suscitèrent une véritable "guerre civile dans le chapitre »! Il est très heureux que le volume s'achève, sous la plume de Raphaël Tassin, par un panorama des solutions adoptées dans les églises rurales de Lorraine. Les modestes sanctuaires de campagne sont généralement les oubliés des enquêtes, alors même qu'ils sont de très loin les plus nombreux, et qu'à leur manière ils portent à la connaissance du peuple chrétien un écho des questions soulevées par les élites canoniales et régulières.

6 La place du chœur foisonne de notations et de suggestions. Il ne pouvait prétendre à une exhaustivité que l'état d'avancement de la recherche n'autoriserait d'ailleurs pas. On souhaiterait seulement qu'une grande rigueur lexicographique permette au curieux de savoir toujours de quoi on lui parle: du sanctuaire, centré sur le maître-autel, ou du chœur au sens strict, où les clercs chantent l'office? d'architecture dans l'acception étroite et vieillie du terme, ou de liturgie ? C'est à cette condition seulement que l'on entrera profondément dans la compréhension des anciens dispositifs cultuels.

\section{AUTEURS}

\section{ALAIN RAUWEL}

Université de Bourgogne. 